\title{
Química e Arqueologia: $0 s$ isótopos de oxigénio e a reconstituição do clima
}

\author{
A. J. C. CRUZ*
}

A datação pela carbono-14 é, provavelmente, a mais conhecida contribuição da química para a arqueologia, a qual, aliás, teve profundas consequências nos estudos arqueológicos [1,2]. No entanto, outras técnicas de datação são também actualmente utilizadas $[3,5]$ e, por outro lado, a colaboração de modo algum se limita a esse campo [2,6-7].

Com efeito, cedo a arqueologia reconheceu 0 interesse da quimica para a resolução de problemas próprios. Desde 1796, pelo menos, encontram-se na literatura científica europeia testemunhos da relação entre as duas ciências, embora só na segunda metade do século $\mathrm{XIX}$ eles surjam com mais frequência [8]. Em Portugal, antes do fim de oitocentos faz-se, o estudo químico de alguns objectos pré-históricos de cobre e de bronze [9].

Actualmente essa colaboração processa-se sobretudo segundo cinco direcções: a prospecção, a datação, a caracterização dos materiais e das tecnologias, a paleoecologia e a conservação [2,6-7].

\section{A química, A PALEOECOLOGIA E O AMBIENTE}

0 grande objectivo da paleoecologia é 0 da reconstituição das condições ecológicas no passado, entre as quais 0 clima desempenha, como hoje, um papel fundamental.

A importância dessa reconstituição para a arqueologia advém do facto de que é do ambiente que o homem extrai os meios necessários à própria vida $\mathrm{e}$ às suas diversas actividades materiais. No entanto, o quadro ambiental do presente não pode ser extrapolado para o passado. Na realidade, todo o planeta ao longo da sua história tem estado sujeito a variações significativas das condições ambientais. Desde o aparecimento do homem, há mais de 2 milhões de anos, a superfície do globo foi profundamente modificada por acumulação e fusão dos glaciares, descidas e subidas do nivel dos mares, desnivelamentos de centenas de metros provocados pelos movimentos tectónicos, erosão das formas do relevo, ocupação e abandono dos espaços pela vegetação e pela fauna, acção do homem. No curto intervalo de tempo (à escala geológica) decorrido desde 0 aparecimento do homem actual no espaço actualmente europeu, há cerca de 3 dezenas de milhares de anos, essas modificações não deixaram de ser importantes: 0 mar já esteve mais de 100 metros abaixo do seu actual nivel, nalgumas regiões a temperatura média já foi mais de $10^{\circ} \mathrm{C}$ inferior à do presente, espaços outrora ocupados por lagos e por alguma vegetação são hoje desertos. Mesmo nas últimas centenas de anos é possível analisar fases climáticas bem diferenciadas $[10,11]$.

Vê-se assim que a arqueologia levanta hoje questões de âmbito geral, muitas delas não limitadas ao passado mas, pelo contrário, bem actuais e importantes como, por exemplo, as colocadas pela relação entre 0 homem e 0 ambiente. Por isso, "é uma evidência que aquilo a que poderemos chamar a 'reconstituição do passado humano' já se não faz só com a arqueologia ou a história concebidas na sua metodologia ainda hoje habitual, e que os mais diversos investigadores, desde que pautados por um objectivo comum, podem, se unirem os seus esforços, dar passos importantíssimos na resolução de questões de uma actualidade científica enorme, que está muito para além da curiosidade sobre a realidade concretamente acontecida, e tem implicações imprevisiveis em numerosos sectores" [12].

\section{OS REgISTOS PALEOCLIMÁTICOS}

Há sobretudo dois tipos de registos geológicos que fornecem informação de natureza química sobre o clima no passado: os gelos dos glaciares e os depósitos de carbonatos.

Os glaciares são constituídos essencialmente por água na forma de gelo e podem ter espessuras superiores a $2 \mathrm{Km}$, as quais correspondem a períodos de acumulação de centenas de milhares de anos. No entanto, contêm igualmente gases aprisionados assim como outras impurezas solúveis e insolúveis. Enquanto a composição isotópica da água está relacionada com parâmetros climáticos, como adiante se explica, as outras substâncias presentes nos gelos permitem a reconstituição de alguns aspectos da composição da atmosfera no passado, os quais, por sua vez, dependem dos ciclos biogeoquímicos e da circulação atmosférica $[13,14]$.

Os depósitos de carbonatos podem ter diferente origem: biológica ou inorgânica. No primeiro caso incluem-se as conchas de animais marinhos como os foraminíferos que, com o tempo, se acumulam no fundo dos oceanos. Entre os carbonatos inorgânicos contam-se os depósitos formados nos fundos dos lagos, os depósitos formados no interior dos solos das regiões áridas e os depósitos estalactíticos e estalagmíticos das grutas.

Em qualquer um dos casos, a existência dos depósitos continentais, só por si, já tem implicações climáticas - por exemplo, o crescimento das estalactites é reduzido em períodos glaciais. Além disso, nomeadamente os depósitos das grutas, contêm impurezas, como os pólens, que permitem a reconstituição do tipo de vegetação $e$, indirectamente das condições ecológicas. No caso dos foraminiferos, é possivel a utilização de técnicas biológicas de reconstituição climática que se baseiam nas proporções entre as diferentes espécies e estimar parâmetros climáticos como a temperatura superficial do mar. 


\section{artigos}

A química tem, no entanto, um papel importante na interpretação destes depósitos. Nomeadamente, as razões isotópicas dos elementos leves estão relacionadas com parâmetros ambientais.

\section{O FRACCIONAMENTO ISOTÓPICO DOS ELEMENTOS LEVES}

As propriedades termodinâmicas das moléculas que contêm diferentes isótopos estáveis dos elementos mais leves da tabela periódica, como 0 hidrogénio, o carbono, o oxigénio e 0 enxofre, em virtude da diferença de massa, diferem ligeiramente [15].

Devido ao facto de as moléculas com isótopos mais leves terem, relativamente às moléculas com isótopos mais pesados, maior energia de vibração, os compostos formados pelos isótopos mais leves apresentam uma maior pres- são de vapor, pelo que, por exemplo durante a vaporização da água, a fase líquida fica, relativamente à fase gasosa, enriquecida nos isótopos de hidrogénio $\mathrm{e}$ de oxigénio mais pesados, ${ }^{2} \mathrm{H} \mathrm{e}{ }^{18} 0$, e empobrecida nos isótopos mais leves, ${ }^{1} \mathrm{H} \mathrm{e}{ }^{16} 0$. De um modo geral, durante qualquer mudança de fase, a fase mais densa fica mais concentrada nos isótopos mais pesados [16,17].

Tal separação é denominada de fraccionamento isotópico e na natureza ocorre em diferentes circunstâncias. Aqui considera-se apenas o fraccionamento do oxigénio durante 0 ciclo geoquímico da água e durante a precipitação do carbonato de cálcio, pois são estes os casos que, de um modo geral, mais interessam à arqueologia. No entanto, para os períodos mais recentes, a composição isotópica dos anéis das árvores fornece igualmente importantes informações de natureza paleoecológica [18].

\section{O FRACCIONAMENTO ISOTÓPICO DO OXIGÉNIO DURANTE $O$ CICLO GEOQUÍMICO DA ÁGUA}

Um dos passos fundamentais no ciclo geoquímico da água é a evaporação à superfície dos oceanos (fig. 1). Nesse processo, devido à pequena diferença das propriedades termodinâmicas, como atrás se disse, a água do mar, relativamente à atmosfera, fica enriquecida em ${ }^{18} 0$ e empobrecida em ${ }^{16} 0$. Ou seja: a razão ${ }^{18} 0 /{ }^{16} 0$ é maior na água do oceano do que na atmosfera. 0 vapor de água é, porém, parcialmente condensado, dando origem às nuvens $\mathrm{e}$, posteriormente, à

Fig. 1 - Representação esquemática do ciclo geoquímico da água. Setas ascendentes: evaporação; setas descendentes: precipitação; setas horizontais: trocas oceanocontinentes. Cada seta corresponde a $\sim 30$ mil km ${ }^{3}$ de água [Suzanne Daveau, 0 Ambiente Geográfico Natural, Lisboa, Imprensa Nacional - Casa da Moeda (1976)].

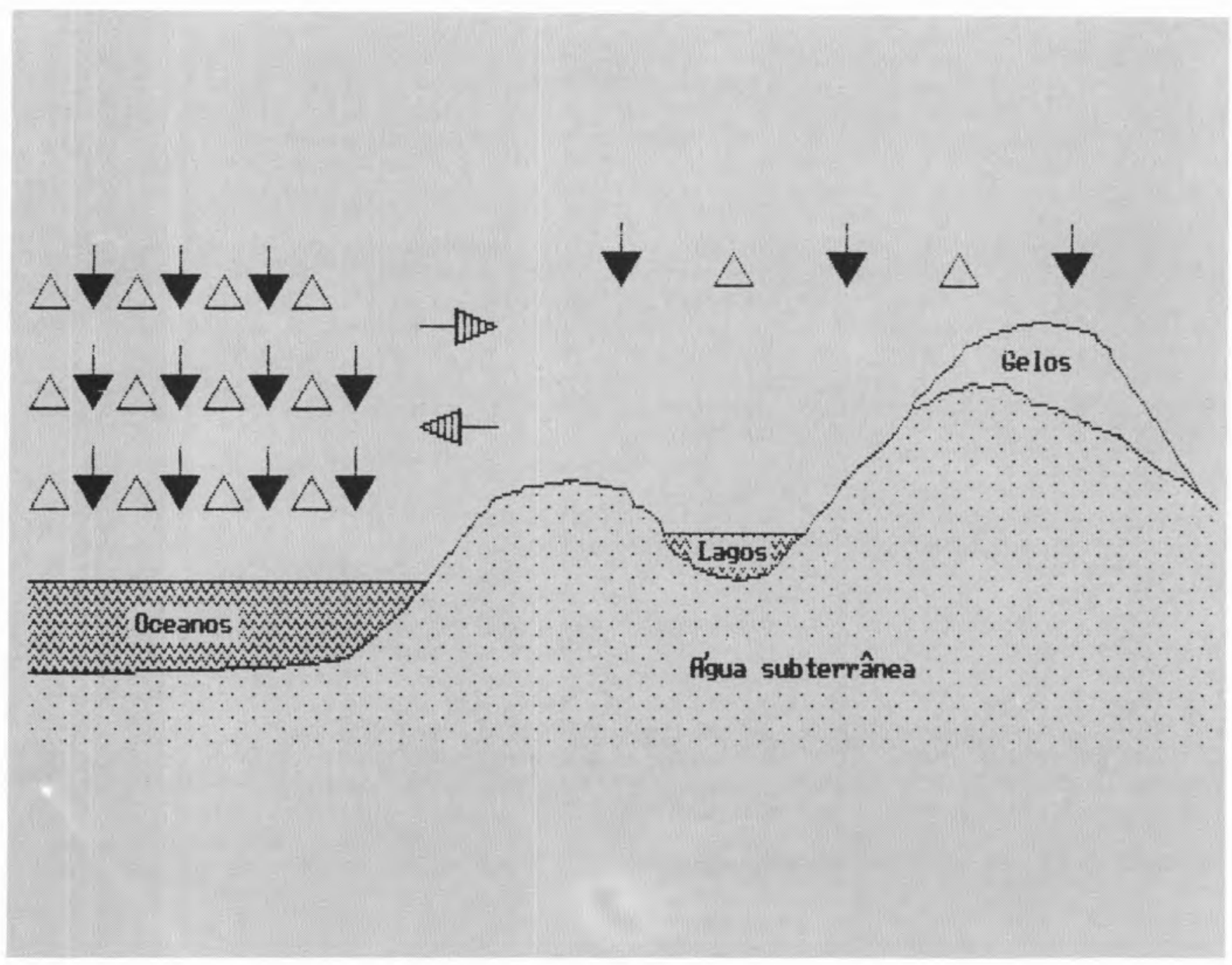




\section{artigos}

precipitação na forma de chuva. Durante este processo dá-se um segundo fraccionamento, ficando a água não condensada existente na atmosfera concentrada nos isótopos mais leves.

Quando se verifica a sublimação desse vapor de água forma-se gelo e este, por conseguinte, tem uma razão ${ }^{18} 0 /{ }^{16} 0$ bastante inferior à da água do mar. Assim, a diferença entre essa razão nos gelos Antárticos e num padrão de água do mar média (Standard Mean Ocean Water ou SMOW) pode ser de -50 a $-60 \%$.

Esta diferença, expressa em permilagem, entre 0 valor da razão ${ }^{18} 0 /{ }^{16} 0$ numa amosra e o correspondente valor num padrão (normalmente, o SMOW no caso das amostras de águas [19]; $0 P D B$ ou Pee Dee Belemnite, um belemnite fóssil com origem na formação de Pee Dee, EUA, no caso das amostras de carbonatos [20]) é habitualmente designada por $\delta^{18} 0$;

$$
\delta^{18} 0=1000 \times \frac{\left({ }^{18} 0 /{ }^{16} 0\right)-\left({ }^{18} 0 /{ }^{16} 0\right)_{\text {PADPÃOO }}}{\left({ }^{18} 0 / /^{16} 0\right)_{\text {PADRÃO }}}
$$

Portanto, no que diz respeito ao ciclo geoquímico da água, tem-se a seguinte sequência:

$\delta^{18} 0$ (oceanos) $>\delta^{18} 0$ (chuva) $>\delta^{18} 0$ (neve).

As diferenças energéticas entre os diferentes isótopos são tanto maiores quanto menor for a temperatura, pelo que a eficiência do fraccionamento isotópico do oxigénio aumenta com a diminuição da temperatura. Assim, a fig. 2 mostra que os últimos $10 \mathrm{mil}$ anos foram consideravelmente mais quentes do que o período imediatamente anterior

\section{O FRACCIONAMENTO ISOTÓPICO DO OXIGÉNIO DURANTE A PRECIPITAÇÃO DOS CARBONATOS}

A solubilização e a precipitação do carbonato de cálcio, que existe sobretudo na forma de calcite, são dois importantes processos químicos que ocorrem na natureza, dando origem por exemplo, à formação das grutas e à formação das rochas calcárias. Esses processos dão-se segundo uma série de equilíbrios nos quais participam as fases gasosa, líquida e sólida. Por exemplo, a precipitação do carbonato de cálcio na água do mar pode ser descrita de um modo simplificado pelas seguintes equações [21]:

$$
\begin{gathered}
\mathrm{CO}_{2}(\mathrm{~g}) \rightleftharpoons \mathrm{CO}_{2}(\mathrm{aq}) \\
\mathrm{CO}_{2}(\mathrm{aq})+\mathrm{H}_{2} \mathrm{O}(\mathrm{aq}) \rightleftharpoons \mathrm{H}_{2} \mathrm{CO}_{3}(\mathrm{aq}) \\
\mathrm{H}_{2} \mathrm{CO}_{3}(\mathrm{aq}) \rightleftharpoons \mathrm{H}^{+}(\mathrm{aq})+\mathrm{HCO}_{3}^{-}(\mathrm{aq}) \\
\mathrm{HCO}_{3}^{-}(\mathrm{aq}) \rightleftharpoons \mathrm{H}^{+}(\mathrm{aq})+\mathrm{CO}_{3}^{2-}(\mathrm{aq}) \\
\mathrm{CO}_{3}^{2-}(\mathrm{aq})+\mathrm{Ca}^{2+}(\mathrm{aq}) \rightleftharpoons \mathrm{CaCO}_{3}(\mathrm{~s}) .
\end{gathered}
$$

0 equilibrio entre 0 dióxido de carbono e a água permite a troca isotópica do oxigénio, por exemplo

$$
\frac{1}{2} \mathrm{C}^{16} \mathrm{O}_{2}(\mathrm{aq})+\mathrm{H}_{2}{ }^{18} \mathrm{O} \rightleftharpoons \frac{1}{2} \mathrm{C}^{18} \mathrm{O}_{2}(\mathrm{aq})+\mathrm{H}_{2}{ }^{16} \mathrm{O}
$$

pelo que a composição isotópica do carbonato precipitado reflecte a composição isotópica do meio aquoso. Porém, esse equilibrio traduz-se por um enriquecimento da fase sólida no isótopo mais pesado. Assim,

$$
\delta^{18} 0 \text { (carbonato) }>\delta^{18} 0 \text { (solução) }
$$

ou, numa notação frequentemente empregue, em que 0 índice $c$ diz respeito ao carbonato e 0 índice $w$ (de water) à solução,

$$
\delta^{18} 0_{c}>\delta^{18} 0_{w} .
$$

0 equilíbrio está relacionado com a temperatura através da expressão [22]

$$
\begin{aligned}
\mathrm{t} /{ }^{\circ} \mathrm{C} & =16,9-4,38\left(\delta^{18} 0_{c}-\delta^{18} 0_{w}\right)+ \\
& +0,10\left(\delta^{18} 0_{c}-\delta^{18} 0_{w}\right)^{2} .
\end{aligned}
$$

No entanto, o estabelecimento de uma escala de temperaturas para 0 passado não é fácil a partir dos dados químicos. Se a determinação de $\delta^{18} O_{c}$ é facilmente feita através da análise dos depósitos de carbonatos, dificilmente são encontrados registos, como algumas inclusões de fluídos nos depósitos calcários das grutas, que permitam a determi-

Fig. 2 - A variação de $\delta^{18} 0$ nos gelos da Gronelândia nos últimos 15 mil anos (primeiros $1200 \mathrm{~m}$ de uma coluna de amostragem com $12 \mathrm{~cm}$ de diâmetro) [W. Dansgaard, S. J. Johnsen, J. Moller, C. C. Langway Jr., Science, 166 (1969) 377.]

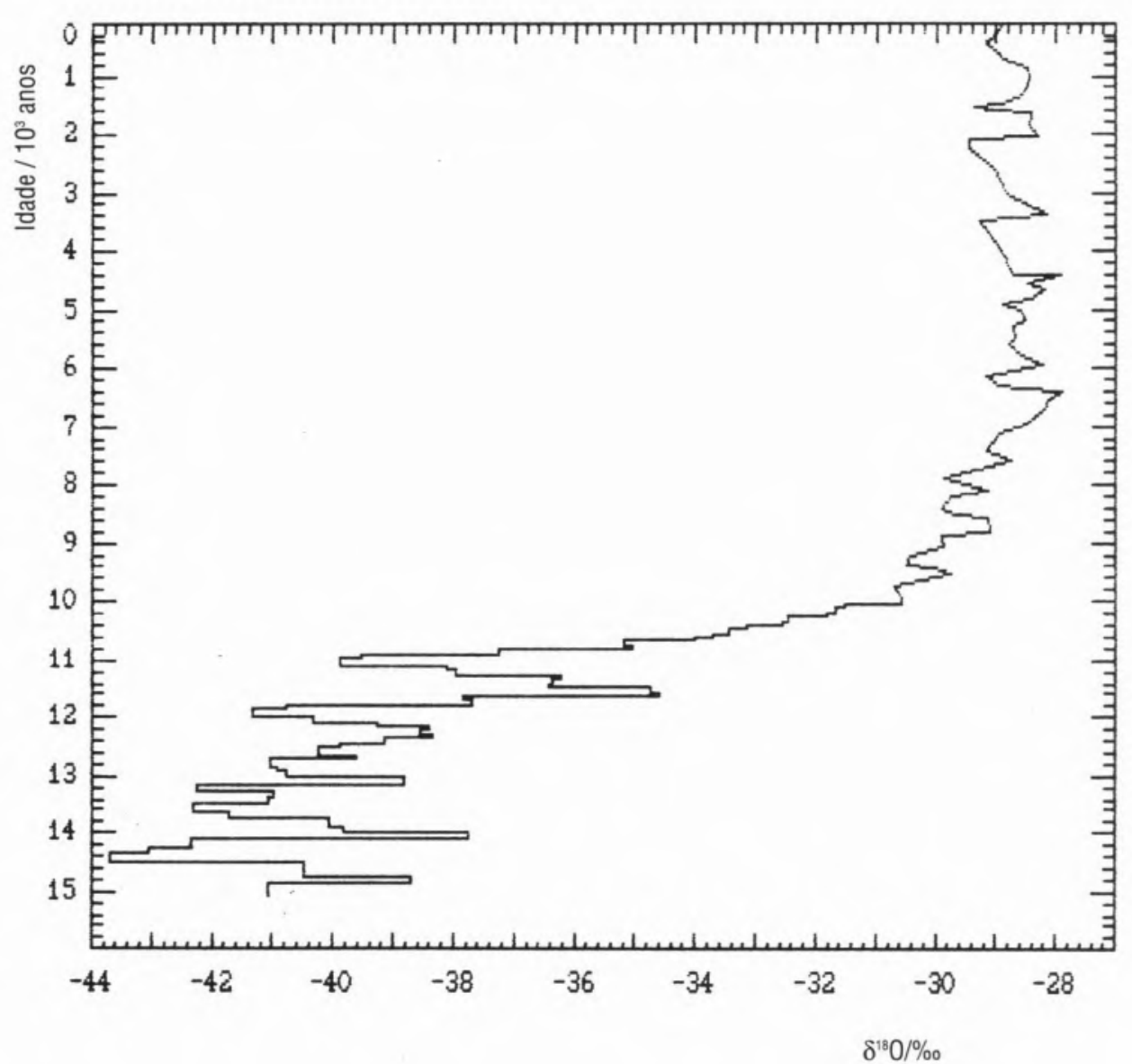




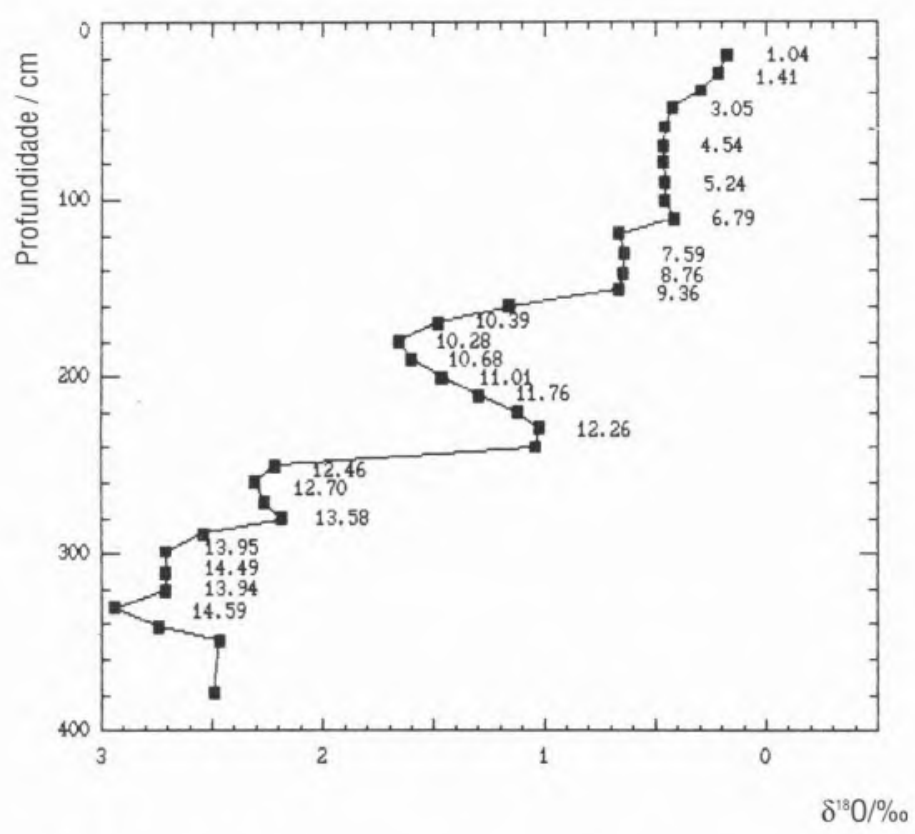

Fig. 3 - A variação de $\delta^{18} 0$ nos foraminiferos (Globigerina bulloides) de uma coluna de amostragem recolhida no fundo do oceano Atlântico, a 3135 $\mathrm{m}$ de profundidade, próximo da extremidade sudoeste de Portugal, correspondente ao periodo posterior ao máximo da última glaciação. Os números ao lado dos pontos correspondem a dataçöes por carbono-14 expressas em milhares de anos antes do presente [E. Bard, M. Arnold, P. Maurice, J. Duprat, J. Moyes, J.-C. Duplessy, Nature, 328 (1987) 791.]

nação de $\delta^{18} 0_{w}$ correspondente ao meio aquoso no momento da precipitação.

Porém, só por si, 0 valor de $\delta^{18} 0$ do carbonato permite obter outras informações igualmente úteis para a reconsti tuições climática, como de seguida brevemente se descreve.

Um dos registos mais frequentemente utilizado é constituído pelas conchas dos foraminiferos das zonas profundas do oceano onde a temperatura da água é muito estável e próxima de $0{ }^{\circ} \mathrm{C}$. Assim, mesmo em períodos glaciares, a variação do parâmetro $\delta^{18} 0$ desses foraminíferos não traduz qualquer variação apreciável de temperaratura, variação que é praticamente inexistente, mas a variação da composição isotópica da água do mar. Esta, por sua vez, devido ao fraccionamento existente durante 0 ciclo geoquímico da água, depende da quantidade dos de degelo são marcados por uma rápida diminuição de $\delta^{18} 0$, motivo porque a análise isotópica das conchas dos foraminiferos tem sido especialmente útil para 0 estudo e reconstituição da época que se seguiu ao máximo da última glaciação (ocorrido há cerca de 18 mil anos), 0 qual é bastante complexo nomeadamente pela existência de curtos períodos de agravamento climático como há cerca de 11 mil anos (fig. 3).

Nos depósitos de carbonatos continentais a interpretação dos resultados da análise isotópica é mais complicada e é necessário distinguir duas situações [23].

Quando os carbonatos são precipitados de meios que não estão sujeitos a fenómenos de evaporação, como nas regiōes frias ou como no interior das grutas, a composição isotópica dos carbonatos traduz o equilibrio existente com a água das chuvas. Desse modo o valor de $\delta^{18} 0$ constitui um indicador da temperatura de condensação e, indirectamente, da temperatura à superficie do globo terrestre.

Em meios geográficos em que se verifica uma importante evaporação, como por exemplo nas regiões secas, a composição da solução na qual se dá a precipitação é sobretudo condicionada pela relação entre a afluência de água (a qual, na ausência de contribuições subterrâneas, é devida à chuva) e a evaporação. Esta conduz a um aumento de $\delta^{18} 0$ na água enquanto a chuva conduz a uma diminuição. Assim, $\delta^{18} 0$ constitui sobretudo um índice da relação entre a chuva e a evaporação.

\section{AGRADECIMENTO}

Agradece-se à Junta Nacional de Investigação Científica e Tecnológica (JNICT) a bolsa concedida através do
Programa Ciência para o estudo geoquímico no âmbito do qual este texto constitui uma breve reflexão preliminar.

\section{REFERÊNCIAS}

1. J. M. Peixoto Cabral, in Química e Sociedade, A. Romão Dias, J. J. Moura Ramos (eds.), Lisboa, Liv. Escolar Editora - Soc. Port. Química (1990). 2. J. M. Peixoto Cabral, Colóquio/Ciências, 7 (1991) 58.

3. M. W. Rowe, J. Chem. Educ., 63 (1986) 16

4. T. Cairns, Anal. Chem., 48 (1976) 266A.

5. E. P. Manche, J. Chem. Educ., 56 (1979) A273, A303, A341.

6. J. B. Lambert, J. Chem. Educ., 60 (1983) 345

7. Z. Gotfer, Archaeological Chemistry, New York. Wiley (1980).

8. A. E. A. Werner, Anal. Chem., 40 (1968) 28 A.

9, A. Bensaúde, Com. Comissão Trab. Geol. Port. 2 (1888) 119

10. B. J. Skinner, S. C. Porter, Physical Geology, New York, Wiley (1987).

11. T. M. L. Wigley, M. J. Ingram, G. Farmer (eds.), Climate and History. Studies in past climates and their impact on Man, Cambridge, Cambridge U.P. (1981).

12. Vitor Oliveira Jorge, Arqueologia, 8 (1981) 5. 13. R. J. Delmas, M. Legrand in H. Oeschger, C. C. Langway Jr. (eds.), The Environmental Record in Glaciers and Ice Sheets, New York, Wiley (1989). 14. M. de Angelis, N. I. Barkov, V. N. Petrov, Nature 325 (1987) 318.

15. H. C. Urey, J. Chem. Soc. 47 (1947) 562. 16. K. B. Krauskopf, Introduction to Geochemistry, $2^{\text {nd }}$ ed., Singapura, McGraw-Hill (1982).

17. B. Mason, C. B. Moore, Principles of Geochemistry, $2^{\text {nd }}$ ed., New York, Wiley (1982).

18. J. Gray, in Climate and History. Studies in past climates and their impact on Man, T. M. L. Wigley, M. J. Ingram, G. Farmer (eds.), Cambridge, Cambridge U.P. (1981).

19. H. Craig, Science, 133 (1961) 1833.

20. H. Craig, Geochim. Cosmochim. Acta, 12 (1957) 133.

21. G. Skirrow, in Chemical Oceanography, J. P. Riley, G. Skirrow (eds.), vol. 1, London, Academic Press (1965).

22. J. R. O'Neil, L. H. Adami, S. Epstein, U. S. Geol. Surv. J. Res., 3 (1975) 623.

23. F. Gasse, R. Téhet, A. Durant, El. Gilbert, J.-C. Fontes, Nature, 346 (1990) 141.

* Centro de Química-Física e Radioquímica, Faculdade de Ciências, 1294 Lisboa Codex Endereço actual: Instituto José de Figueiredo, Rua das Janelas Verdes, 1200 Lisboa 